\title{
Variants in CDHR3, CACNACI, and LTA Genes Predisposing Sensitivity and Response to Warfarin in Patients with Cardiovascular Disease
}

This article was published in the following Dove Press journal: International Journal of General Medicine

\author{
Mansour A Alghamdi (D) ${ }^{1,2}$ \\ Laith AL-Eitan $\mathbb{D D}^{3}$ \\ Rami Alkhatib (D ${ }^{3}$ \\ Ahmad Al-Assi (iD ${ }^{4}$ \\ Ayah Almasri ${ }^{3}$ \\ Hanan Aljamal (D) ${ }^{3}$ \\ Hatem Aman ${ }^{3}$ \\ Rame Khasawneh (iD ${ }^{5}$
}

'Department of Anatomy, College of Medicine, King Khalid University, Abha, 6142I, Saudi Arabia; ${ }^{2}$ Genomics and Personalized Medicine Unit, College of Medicine, King Khalid University, Abha, 6I42I, Saudi Arabia; ${ }^{3}$ Department of Biotechnology and Genetic Engineering, Jordan University of Science and Technology, Irbid, 22I I0, Jordan; ${ }^{4}$ Faculty of Medicine, Jordan University of Science and Technology, Irbid, 22II0, Jordan;

${ }^{5}$ Department of Hematopathology, King Hussein Medical Center (KHMC), Royal Medical Services (RMS), Amman, III I8, Jordan
Correspondence: Laith AL-Eitan Department of Biotechnology \& Genetic Engineering/Faculty of Science and Arts, Jordan University of Science and Technology, P.O.Box 3030, Irbid, 22II0, Jordan

Tel +962-2-7201000 ext 23464

Email Ineitan@just.edu.jo
Introduction: Warfarin has been in use for more than 60 years; however, it has serious side effects including major bleeding. The high interpatient variability in the required dose impacts the sensitivity and responsiveness to warfarin in different patients. This study aims to assess the influence of CDHR3, CACNAC1, and LTA gene polymorphisms on the variability of warfarin dose requirements and susceptibility to coronary heart disease in the Jordanian population.

Methods: This study was conducted in the anti-coagulation clinic in Queen Alia Heart Institute in Amman, with 212 patients in total. Three SNPs were genotyped within CDHR3 (rs10270308), CACNAC1 (rs216013), and LTA (rs1041981) genes.

Results: Our findings revealed that patients with LTA polymorphism are more prone to warfarin sensitivity than others. Furthermore, carriers of the LTA polymorphism needed a lower initial dose of warfarin and are associated with less variation in doses required to achieve target INR.

Conclusion: The current study could help in understanding the role of genetic variability in warfarin dosing and matching patients to different treatment options. Clinical applications of these findings for warfarin treatment may also contribute to improving the efficacy and safety of warfarin treatment in Jordanian patients with cardiovascular disease.

Keywords: warfarin, pharmacogenetics, single nucleotide polymorphisms, INR, stroke

\section{Introduction}

Anticoagulant therapy has high efficacy and applicability in many pathologies and it has been used heavily lately. ${ }^{1,2}$ For example, warfarin is known to be the most commonly used anticoagulant and has been used in clinical medicine for more than 40 years now. ${ }^{3}$ It is an oral medication that works as a competitive inhibitor of vitamin $\mathrm{K}$ epoxide reductase complex 1 ( $\mathrm{KKORC1}$ ) and reduces the regeneration of vitamin $\mathrm{K}$, which is needed as a cofactor for the activation of several clotting factors (eg, II, VII, IX and X) and anticoagulant proteins (eg, S, C and Z). ${ }^{4,5}$ Warfarin is a synthetic compound that is administered as a racemic mixture containing $50 \% \mathrm{~S}$ and $50 \% \mathrm{R}$ enantiomers due to the asymmetric carbon in its structure. ${ }^{6,7}$ It is mainly metabolized in the liver by cytochrome $\mathrm{P} 450 .{ }^{7}$ Warfarin is primarily used in the prevention of thrombo-embolic complications caused by many diseases including cardiac valve replacement and atrial fibrillation. ${ }^{8}$ It has been proven that warfarin lower the risk of developing stroke by $64 \%$ in atrial fibrillation patients. ${ }^{2}$ Other indications for warfarin use include: prophylaxis and treatment of arising 
pulmonary embolisms, venous thrombosis, ischemic stroke, myocardial infarction, valve prosthesis, intracardiac thrombus and other cardiovascular diseases. ${ }^{2,6,8}$

However, warfarin has been characterized by a narrow therapeutic index, slow onset-of-action, titrated dosing, and a high interpatient variability of pharmacokinetic and pharmacodynamics parameters. ${ }^{9}$ Therefore, warfarin is still considered one of the top 10 medications associated with adverse effects. If the dose is too high, it may cause a major bleed. ${ }^{10}$ In fact, $2-3 \%$ of patients starting warfarin have a major bleed in the first year but the hemorrhage rate is based on the International Normalized Ratio (INR); an expression of the patient's prothrombin period. ${ }^{11,12}$ If the INR is too low, patients are at risk of thromboembolic disease. ${ }^{4}$ An INR of $2-3$ is usually considered as the therapeutic range of anticoagulation. ${ }^{8}$ However, even when holding patients within a small range of the target INR, safety and efficacy of therapy are not guaranteed. ${ }^{13,14}$ Therapeutic guidelines have recommended introducing warfarin near the expected maintenance dose and then modifying the dose by trial and error to reduce such adverse effects throughout the duration of use of warfarin and particularly during the initiation phase. ${ }^{5}$

The dosage of warfarin has been shown to be influenced by many clinical factors including vitamin $\mathrm{K}$ usage, age, and clinical characteristics of the patient, comorbidities, concomitant drugs, diet, and genetics. ${ }^{2,15}$ The genetic causes of warfarin response variation have been extensively studied over the past 2 decades. ${ }^{2}$ Among these, variants in genes encoding warfarin target (eg, VKORC1) and genes encoding warfarin metabolism (eg, CYP2C9) were affected by time and dose to meet target INR in patients treated with warfarin. ${ }^{16}$ Nonetheless, other genes (eg, CYP4F2, epoxide hydrolase I (EPHX1), gammaglutamyl carboxylase $(G G C X)$, calumenin $(C A L U)$ and CYP2C19) have also been studied in different ethnic groups. $^{8,17}$ Dosage of warfarin can be predicted using a number of algorithms that include both clinical and genetic information. ${ }^{18}$ The inclusion of the genetic information in addition to the clinical characteristics into the dosing algorithms has improved the predictability of warfarin dose for each patient. ${ }^{18-20}$ The Lymphotoxin- $\alpha($ LTA $)$ gene is a proinflammatory cytokine that is expressed in atherosclerotic lesions. ${ }^{2,21,22}$ Some studies have shown that the risk of ischemic strokes and coronary artery disease is substantially affected by LTA polymorphisms. ${ }^{2,23}$ The formation of adhesion molecules and cytokines is induced by $L T A$, indicating its contribution to the pathogenesis of atherosclerosis, coronary artery disease and inflammation which in turn might alter the dose needed for warfarin to reach the target INR. ${ }^{2}$ Another gene has been also linked with cardiovascular disease in hypertensive patients is calcium voltage-gated channel subunit alpha1 A $(C A C N A C 1) .{ }^{18,24}$ This gene has become of interest in previous studies where it showed some significance to warfarin dosage. ${ }^{26}$ The Cadherin-related family member 3 (CDHR3) gene have been strongly linked to asthma and some other studies have established an inverse relation with myocardial infarction. ${ }^{25-27}$ Therefore, this study aimed to assess and evaluate the influence of CACNAC1, LTA, and CDHR3 variants on warfarin dosage requirement among Jordanian patients.

\section{Materials and Methods Study Design and Patients}

In accordance with the Declaration of Helsinki, a total of 220 patients visiting the Queen Alia Heart Institute were included in this study. Between January 2014 and November 2015, all cardiovascular patients began anticoagulation treatment at anti-coagulation clinic in AmmanJordan. Participating patients should have been at least 18 years of age before beginning therapy in order to be included in our analysis and should have attended the clinic regularly for at least 3 months. Patients who were taking any pharmacokinetics interacting drugs according to Dutch standards for the treatment of coumarin interactions, ${ }^{28}$ have lost their clinical data, alcoholics or were pregnant throughout the time of the study were totally excluded from the study. Patients who met the inclusion criteria were interviewed, had the study goals clarified, and signed a consent form of participation. A written informed consent from all participants has also been obtained. This research was approved by the Jordan University of Science and Technology (JUST) (ethical code number 13/78/2014).

Initially, 300 patients out of the 350 who were originally evaluated were referred to participate in the study. According to the exclusion criteria, a total of 80 was excluded. The remaining 220 consented to participate in our study. Eight patients also were excluded from this study due to either degradation of DNA samples or low DNA content. Finally, out of the remaining 212 patients, 139 only reached the stabilization phase. Pharmacogenetics analysis was conducted based on two phases: the initiation phase relies on data of 212 patients 
and the stabilization phase depends on 139 patients who have reached the maintenance phase of treatments as previously described by AL-Eitan et al. ${ }^{29}$

\section{Data Collection and Follow-Up Time}

Between January 2014 and November 2015, data were collected for all patients including a range of demographic characteristics (eg, age, gender, smoking, eating habits, and Body Mass Index). Moreover, clinical data (eg, the indication for prescribing anticoagulants, current INR, therapeutic INR, the dosage of anticoagulant use, duration of use, hemorrhage, lipid profile (low-density lipoprotein; LDL level, highdensity lipoprotein; HDL level, and cholesterol), comorbidities and other medications in use) was also collected.

\section{SNP Selection and Genotyping}

The targeted SNPs for analysis were extracted from the National Biotechnology Information Center (NCBI) SNP database, and the Applied Biosystems SNP database. For the LTA, CDHR3, and CACNAC1 genes, 3 SNPs have been selected. Table 1 lists the names, IDs and positions of the selected genes. Genomic DNA was extracted using the Wizard Genomic DNA Purification Kit (Promega Corporation, Madison, WI, USA). Samples met the quantitative requirements of the study were subsequently imported to the Australian Genome Research Facility (AGRF) for genotyping using the Mass ARRAY ${ }^{\circledR}$ System (iPLEX GOLD) (Sequenom, San Diego, CA, USA). Upon request, the primers for the LTA, CDHR3, and CACNACl genes and the Mass ARRAYTM system protocol information used are available.

\section{Outcome Measure}

In order to assess the main objective of the research, which is the sensitivity to warfarin; patients were first divided into three main classes based on the Gordon study. ${ }^{30}$ These groups were as follows:

Table I Genes and SNPs Characteristics

\begin{tabular}{|l|c|c|c|c|}
\hline Gene & SNP & $\begin{array}{c}\text { Chr. } \\
\text { Position* }\end{array}$ & Alleles & $\begin{array}{c}\text { Variant } \\
\text { Type }\end{array}$ \\
\hline CDHR3 & $\mathrm{rs} 10270308$ & $7: 106030821$ & T/C & Synonymous \\
CACNACI & $\mathrm{rs} 216013$ & $12: 2620466$ & A/G & Intron \\
LTA & $\mathrm{rs} 1041981$ & $6: 31573007$ & C/A & Missense \\
\hline
\end{tabular}

Note: *From NCBI Human Genome Assembly Build.
1. High Metabolizers or warfarin resistance group (this category includes patients who needed $>49 \mathrm{mg}$ of warfarin per week).

2. Moderate Metabolizers or warfarin response groups (this category includes patients who needed between 21 and $49 \mathrm{mg}$ of warfarin per week).

3. Low metabolizers or warfarin-sensitive groups (this category includes patients who needed $<21 \mathrm{mg}$ of warfarin per week).

Warfarin responsiveness was the second goal of the study and thus patients were further classified into 3 other categories according to Higashi et al, ${ }^{31}$ that are:

1. Good Responders (these patients have an INR that is in the target range, ie, therapeutic range).

2. Low Responders (these patients have an INR that is below the target range).

3. Ultra-Responders (these patients have an INR above the target range).

Finally, the definition of the maintenance dose is the average of all doses given to the patient during the period with stable anticoagulation. All weekly settled doses for at least two following visits under therapeutic INR were used to estimate the stable maintenance dose.

\section{Statistical Analysis}

The statistical package for social sciences (SPSS, v21.0) was used in the current study. The Chi-square test, the unidirectional variance analysis, the one-way ANOVA followed by Turkey HSD post hoc multiple comparison test, and the Kruskal Wallis non-parametric correlation test are used to assess which of the SNPs are correlated with warfarin response. The minor allele frequency (MAF) and the Hardy-Weinberg balance (HWE) $P$-values were determined for each SNP.

\section{Results}

The study group comprised of 212 unrelated Jordanian (Arab) patients treated with warfarin as anticoagulant treatment. The mean age $( \pm \mathrm{SD})$ of these patients was $56.03 \pm(17.68)$ years with a range of 18 to 85 years. The median age of the patients was 60 (range: 18 to 85 ). Both genotype and phenotype data were available for these patients. Our study included a total of 212 patients with an average age of $47.6 \pm 17.7$ years in the extensive metabolizer group, 53.2 \pm 15.3 years in the good metabolizer 
Table 2 Association of CDHR3, CACNACI, and LTA SNPs with Warfarin Sensitivity During the Initiation Phase of Treatment with Warfarin in Cardiovascular Patients $(n=2 / 2)$

\begin{tabular}{|c|c|c|c|c|c|c|}
\hline Gene & SNP & Genotype & Sensitive & Moderate & Resistance & Overall $P$-value* \\
\hline CDHR3 & rs 10270308 & $\begin{array}{c}C T \\
P \text {-value } \\
\text { TT } \\
P \text {-value }\end{array}$ & $\begin{array}{c}(2 / 14) 14.3 \% \\
0.99 \\
(30 / 196) 15.3 \% \\
0.99\end{array}$ & $\begin{array}{c}(10 / 14) 71.4 \% \\
0.98 \\
(135 / 196) 68.9 \% \\
0.98\end{array}$ & $\begin{array}{c}(2 / 14) 14.3 \% \\
0.99 \\
(31 / 196) 15.8 \% \\
0.99\end{array}$ & I \\
\hline CACNACI & rs216013 & $\begin{array}{c}\text { AA } \\
P \text {-value } \\
\text { AG } \\
P \text {-value } \\
\text { GG } \\
P \text {-value }\end{array}$ & $\begin{array}{c}(22 / 120) 18.3 \% \\
0.14 \\
(9 / 79) 11.4 \% \\
0.24 \\
(I / I 2) 8.3 \% \\
0.53\end{array}$ & $\begin{array}{c}(77 / / 20) 64.2 \% \\
0.10 \\
(57 / 79) 72.2 \% \\
0.4 I \\
(I I / I 2) 91.7 \% \\
0.92\end{array}$ & $\begin{array}{c}(2 / 120) 17.5 \% \\
0.53 \\
(13 / 79) 16.5 \% \\
0.08 \\
(0 / 12) 0.0 \% \\
0.12\end{array}$ & 0.243 \\
\hline LTA & rsl04198I & $\begin{array}{c}\text { AA } \\
P \text {-value } \\
\text { CA } \\
P \text {-value } \\
\text { CC } \\
P \text {-value }\end{array}$ & $\begin{array}{c}(2 / 20) 10 \% \\
0.50 \\
(I 8 / 106) \quad I 7 \% \\
0.44 \\
(I 2 / 86) 14 \% \\
0.70\end{array}$ & $\begin{array}{c}(I 3 / 20) 65 \% \\
0.69 \\
(79 / 106) 74.5 \% \\
0.08 \\
(54 / 86) 62.8 \% \\
0.11\end{array}$ & $\begin{array}{c}(5 / 20) 25 \% \\
0.25 \\
(9 / 106) 8.5 \% \\
0.003 \\
(20 / 86) 23.3 \% \\
0.02\end{array}$ & 0.05 \\
\hline
\end{tabular}

Note: $* \mathrm{P}$ value $<0.05$ is considered significant.

group, and $54.2 \pm 18.4$ years in the low metabolizer group. These patients included 83 males (59.7\%) and 56 females (40.3\%). The most common co-morbidity in studied patients was hypertension. For further information, the clinical and demographic data are summarized in previously published study by AL-Eitan et al. ${ }^{20}$ The average age for controls was $37.5 \pm 13.7,53.6 \%$ of them were male and $46.3 \%$ were female.

Table 2 shows that LTA gene polymorphism rs 1041981 (CA) is the most common polymorphism in the LTA gene with 106 patients. Significance was found between the polymorphism and warfarin sensitivity

Table 3 Association of CDHR3, CACNACI, and LTA SNPs with Warfarin Sensitivity During the Stabilization Phase of Treatment with Warfarin in Cardiovascular Patients $(n=139)$

\begin{tabular}{|c|c|c|c|c|c|c|}
\hline Gene & SNP & Genotype & Sensitive & Moderate & Resistance & Overall $P$-value* \\
\hline CDHR3 & rs 10270308 & $\begin{array}{c}\text { CT } \\
P \text {-value } \\
\text { TT } \\
P \text {-value }\end{array}$ & $\begin{array}{c}(0 / 9) 0.0 \% \\
0.19 \\
(20 / 128) 15.6 \% \\
0.19\end{array}$ & $\begin{array}{c}(7 / 9) 77.8 \% \\
0.32 \\
(77 / / 28) 60.2 \% \\
0.32\end{array}$ & $\begin{array}{c}(2 / 9) 22.2 \% \\
0.92 \\
(3 \mathrm{I} / / 28) 24.2 \% \\
0.92\end{array}$ & 0.427 \\
\hline CACNACI & $r s 216013$ & $\begin{array}{c}\text { AA } \\
P \text {-value } \\
\text { AG } \\
P \text {-value } \\
\text { GG } \\
P \text {-value }\end{array}$ & $\begin{array}{c}(I I / 77) \quad 14.3 \% \\
0.92 \\
(6 / 55) 10.9 \% \\
0.32 \\
(3 / 6) 50 \% \\
0.01\end{array}$ & $\begin{array}{c}(47 / 77) 61 \% \\
0.84 \\
(35 / 55) 63.6 \% \\
0.69 \\
(3 / 6) 50 \% \\
0.55\end{array}$ & $\begin{array}{c}(19 / 77) 24.7 \% \\
0.84 \\
(14 / 55) 25.5 \% \\
0.76 \\
(0 / 6) 0.0 \% \\
0.16\end{array}$ & 0.117 \\
\hline LTA & rsl04I98I & $\begin{array}{c}\text { AA } \\
P \text {-value } \\
\text { CA } \\
P \text {-value } \\
\text { CC } \\
P \text {-value }\end{array}$ & $\begin{array}{c}(2 / 17) \quad I I .8 \% \\
0.76 \\
(I 1 / 69) 15.9 \% \\
0.62 \\
(7 / 53) 13.2 \% \\
0.76\end{array}$ & $\begin{array}{c}(9 / 17) 52.9 \% \\
0.42 \\
(47 / 69) 68.1 \% \\
0.13 \\
(30 / 53) 56.6 \% \\
0.32\end{array}$ & $\begin{array}{c}(6 / 17) 35.3 \% \\
0.23 \\
(I I / 69) 15.9 \% \\
0.04 \\
(16 / 53) 30.2 \% \\
0.16\end{array}$ & 0.312 \\
\hline
\end{tabular}

Note: $* \mathrm{P}$ value $<0.05$ is considered significant. 
Table 4 Association of CDHR3, CACNACI, and LTA SNPs with Variability on Warfarin Required Doses

\begin{tabular}{|c|c|c|c|c|c|c|}
\hline Gene & SNP & Genotype & Initiation Dose & Overall $P$-value* & Maintenance Dose & Overall $P$-value* \\
\hline \multirow[t]{2}{*}{ CDHR3 } & \multirow[t]{2}{*}{ rs 10270308} & CT & 37.65 [1I.15] & \multirow[t]{2}{*}{0.945} & $38.43[18.17]$ & \multirow[t]{2}{*}{0.515} \\
\hline & & TT & 38.09 [23.77] & & $42.48[\mid 4.8 I]$ & \\
\hline \multirow[t]{3}{*}{ CACNACI } & \multirow[t]{3}{*}{ rs216013 } & AA & 39.13 [28.79] & \multirow[t]{3}{*}{0.593} & $38.68[18.7 \mid]$ & \multirow[t]{3}{*}{0.173} \\
\hline & & AG & $37.51[12.31]$ & & $40.01[17.01]$ & \\
\hline & & GG & 32.27 [9.79] & & $25.67[9.74]$ & \\
\hline \multirow[t]{3}{*}{ LTA } & \multirow[t]{3}{*}{ rsl04I98I } & AA & 41.67 [15.69] & \multirow[t]{3}{*}{0.506} & $43.20[22.5 \mathrm{I}]$ & \multirow[t]{3}{*}{0.006} \\
\hline & & CA & $36.32[28.07]$ & & $33.74[12.08]$ & \\
\hline & & $\mathrm{CC}$ & 39.37 [16.87] & & 43.64 [16.99] & \\
\hline
\end{tabular}

Notes: *P value $<0.05$ is considered significant. Mean standard deviation in square brackets.

during the initiation phase $(P=0.003)$. Nonetheless, the (CC) polymorphism has also shown significance between the polymorphism and the sensitivity to warfarin $(P=0.02)$. None of the $C D H R 3$ gene or $C A C N A C 1$ gene polymorphisms have shown any significance in the initiation phase.

The chi-square test results presented in Table 3 show a significant p-value of 0.01 when it comes to the association of CACNAC1 gene polymorphism (GG) with warfarin sensitivity during the maintenance phase of therapy. Interestingly, $50 \%$ of the (GG) polymorphism of the CACNACl gene are found to be sensitive for warfarin needing less than $21 \mathrm{mg} /$ week to maintain a stable therapeutic INR. Furthermore, the LTA polymorphism (CA) has shown a significant association with warfarin sensitivity. Thus, the LTA gene polymorphism has shown significance in both the initiation and maintenance phases when it comes to warfarin sensitivity.
The ANOVA test revealed a significant association between the LTA gene polymorphisms and the variability on warfarin required doses with a $P$-value of 0.006 (Table 4 ). The (CA) polymorphisms, which showed a significant association with the sensitivity to warfarin in both the initiation and maintenance phases, have a mean initiation dose of $36.32 \pm 28.07 \mathrm{mg}$ which is the second least initiation dose between the studied gene polymorphisms. Remarkably, the (CA) polymorphism values show that the patients needed a lower dose of warfarin as a maintenance dose when compared to the starting initiation dose. The least initiation dose was observed in the (GG) polymorphism of the CACNACl gene $(32.27 \pm 9.79 \mathrm{mg})$. On the other hand, the highest initiation dose was observed in the (AA) polymorphism of the LTA gene $(41.67 \pm 15.69 \mathrm{mg})$. A significance can be deduced with the post-hoc multiple comparisons test (Table 5) between the maintenance dose of the (CA) polymorphism patients when compared to the (CC) polymorphism of the LTA gene $(P=0.009)$.

Table 5 Post Hoc Tests for the Association of CDHR3, CACNACI, and LTA SNPs with Variability on Warfarin Required Doses

\begin{tabular}{|c|c|c|c|c|c|}
\hline \multirow{2}{*}{$\begin{array}{l}\text { Gene } \\
\text { CACNACI }\end{array}$} & \multirow{2}{*}{$\begin{array}{c}\text { SNP } \\
r s 216013\end{array}$} & \multicolumn{2}{|c|}{ Genotype } & \multirow{2}{*}{$\begin{array}{c}\begin{array}{c}\text { Initiation Dose } \\
\text { P-value* }\end{array} \\
0.88\end{array}$} & \multirow{2}{*}{$\begin{array}{c}\begin{array}{c}\text { Maintenance Dose } \\
\text { P-value* }\end{array} \\
0.89\end{array}$} \\
\hline & & $\mathrm{AA}$ & AG & & \\
\hline & & & GG & 0.59 & 0.19 \\
\hline & & $A G$ & $\mathrm{AA}$ & 0.88 & 0.89 \\
\hline & & & GG & 0.75 & 0.15 \\
\hline & & GG & $\mathrm{AA}$ & 0.59 & 0.19 \\
\hline & & & AG & 0.75 & 0.15 \\
\hline \multirow[t]{6}{*}{ LTA } & \multirow[t]{6}{*}{ rsI04I98I } & AA & CA & 0.61 & 0.09 \\
\hline & & & $\mathrm{CC}$ & 0.92 & 0.96 \\
\hline & & $\mathrm{CA}$ & AA & 0.61 & 0.09 \\
\hline & & & CC & 0.63 & 0.009 \\
\hline & & $\mathrm{CC}$ & $\mathrm{AA}$ & 0.92 & 0.96 \\
\hline & & & $\mathrm{CA}$ & 0.63 & 0.009 \\
\hline
\end{tabular}

Notes: *P value $<0.05$ is considered significant. Compare the means of initiation and maintenance dose among all genotypes. Post hoc are not performed for rs 10270308 because it is fewer than three groups. 
Finally, no significant associations were found between the studied SNPs and response to warfarin during the initiation and maintenance phases (Tables S1 and $\underline{\mathrm{S} 2}$ ). Moreover, no significant association was found between the studied SNPs and treatment outcomes (Tables S3 and S4).

\section{Discussion}

Genetic testing for multiple SNPs in different candidate genes was performed to optimize the information and decrease the cost of large degrees of freedom in testing multiple parameters. For example, lymphotoxin-alpha (LTA) is a protein-coding gene, which encodes a cytokine produced by various lymphocytes ${ }^{2}$ and genetic variations in the LTA gene have been linked to a number of inflammatory diseases. ${ }^{32}$ The LTA gene plays a major role in local inflammatory response and regulation of the immune system. ${ }^{32,33}$ Several preliminary studies have suggested the involvement of the LTA gene to the pathogenesis of atherosclerosis and coronary artery disease as it is expressed in atherosclerotic plaques in animal models. ${ }^{2,21,33}$ However, a previous meta-analysis study showed no significant association of the LTA gene and CHD risk. ${ }^{33}$ On the other hand, a more recent metaanalysis study indicated that some LTA polymorphisms have a significant effect on the possibility of having an ischemic stroke in non-hypertensive patients. ${ }^{22}$ A significant association has been established between the LTA SNP rs1041981 and warfarin sensitivity during both initiation and maintenance phases in our study, while a significant association was established between the LTA SNP rs909253 and the warfarin dose and time in Borges et al findings. ${ }^{2}$ A number of gene polymorphisms and their effect on warfarin sensitivity have been studied in different populations of different ethnicities. These studies linked CYP2C9, VKORC1, CYP4F2, EPHX1, CALU, APOE, and PROC with warfarin sensitivity in Caucasians and African Americans. ${ }^{34}$ Recent studies confirmed the presence of an association in the CYP2C9 and VKORC1 polymorphisms and warfarin sensitivity in the Jordanian patients. ${ }^{17,35}$

Our current study did not show any significance between the $C D H R 3$ gene and warfarin sensitivity or responsiveness during the maintenance phase of therapy. The CDHR3 gene that encodes cadherin-related family member 3, have been linked in previous studies to asthma and an increase in hospitalization risk in addition to an increase in the number of exacerbations. ${ }^{24}$
However, to our knowledge, no links have been made in previous literature between CDHR3 polymorphisms and warfarin sensitivity and responsiveness. Thus, further studies are needed to prove an association between the CDHR3 gene and warfarin dosage. The results presented above have demonstrated an association between CACNAC1 (rs216013) and warfarin sensitivity during maintenance phase. CACNACl gene is a membrane calcium-channel encoding gene that has been linked to myocardial infarction. ${ }^{18,26,36}$ Interestingly, the gene has been also linked to bipolar disorder and schizophrenia. ${ }^{37}$ This gene has shown no significance with warfarin maintenance dose in a previous genome-wide study. ${ }^{26}$

Moreover, algorithms have been used in previous studies that included the polymorphisms of certain genes and the clinical information of the patients to predict the appropriate warfarin dose needed for every patient in order to reduce the interpatient variability of warfarin and to avoid the severe side effects of the medication. ${ }^{18}$ The addition of more associated gene polymorphisms to the algorithm will help in the study of an effective warfarin dosing algorithm. Compared to a fixed-dose approach, the European Pharmacogenetic Anticoagulation Trial (EU-PACT) has shown more time in the therapeutic range with the use of a pharmacogenetic algorithm. ${ }^{38,39}$ On the contrary, a study on the US population, the Clarification of Optimal Anticoagulation through Genetics (COAG), deduced that the use of a pharmacogenetic algorithm did not show any enhancement in the time in the therapeutic range. ${ }^{38}$ However, in the Jordanian population and more widely in the MENA (Middle East and North Africa) region, little research has been done to add more gene polymorphisms to the dosing algorithm and to establish a better picture of the genetic variations and their effects on the warfarin sensitivity in the region. This is because pharmacogenomics in the Jordanian population requires more effort and education especially for healthcare provider. ${ }^{40}$ The integration of clinical training and pharmacogenomics training will help achieve obvious benefits for the entire community. There are some limitations to this study, where the study has been done on a small sample size. Therefore, a larger sample size is required to validate and confirm the current findings. In addition, all patients visited the same clinic and to get a more inclusive depiction of the actual Jordanian population, more patients should have been taken from different clinics around Jordan. 


\section{Conclusion}

The current study has shown a considerable linkage between the LTA gene polymorphisms and warfarin sensitivity during the initiation and maintenance phases of warfarin treatment among cardiovascular disease patients in the Jordanian society. Being a carrier for an LTA polymorphism is associated with variation in warfarin dose required to achieve the target or therapeutic INR. However, further studies are needed to validate this finding and confirm the genetic association between $C A C N A C 1$ gene polymorphisms and warfarin sensitivity using a larger sample size. Conclusively, future extended pharmacogenomics study should be conducted to study the effects of more candidate genetic factors and other clinical manifestations in warfarin-sensitive and responsive patients. Finally, the current study could help in understanding the role of genetic variability in warfarin dosing and matching patients to different treatment options. Clinical translation of obtained perception may attribute to increased potency and safety of warfarin treatment in cardiovascular patients.

\section{Acknowledgments}

We would like to thank Queen Alia Heart institute anticoagulation clinic for their generous help during the course of this study.

\section{Funding}

This project was funded under grant number (203/2014) and supported by the Deanship of Research at Jordan University of Science and Technology.

\section{Disclosure}

The authors report no conflicts of interest in this work.

\section{References}

1. Bader LA, Elewa H. The impact of genetic and non-genetic factors on warfarin dose prediction in MENA region: a systematic review. PLoS One. 2016;11(12):e0168732. doi:10.1371/journal.pone.0168732

2. Borges JB, Hirata TD, Cerda A, et al. Polymorphisms in genes encoding metalloproteinase 9 and lymphotoxin-alpha can influence warfarin treatment. J Pharmacogenomics Pharmacoproteomics. 2015;6:143. doi:10.4172/2153-0645.1000143

3. Kaminsky LS, Zhang ZY. Human P450 metabolism of warfarin. Pharmacol Ther. 1997;73(1):67-74. doi:10.1016/s0163-7258(96) 00140-4

4. Sconce EA, Khan TI, Wynne HA, et al. The impact of CYP2C9 and VKORC1 genetic polymorphism and patient characteristics upon warfarin dose requirements: proposal for a new dosing regimen. Blood. 2005;106(7):2329-2333. doi:10.1182/blood-2005-03-1108
5. Tavares LC, Marcatto LR, Santos PC. Genotype-guided warfarin therapy: current status. Pharmacogenomics. 2018;19(7):667-685. doi:10.2217/pgs-2017-0207

6. Al-Eitan LN, Almasri AY, Al-Habahbeh SO. Effects of coagulation factor VII polymorphisms on warfarin sensitivity and responsiveness in Jordanian cardiovascular patients during the initiation and maintenance phases of warfarin therapy. Pharmacogenomics Person Med. 2019;12:1-8. doi:10.2147/pgpm.s189458

7. Kampouraki E, Kamali F. Pharmacogenetics of anticoagulants used for stroke prevention in patients with atrial fibrillation. Expert Opin Drug Metab Toxicol. 2019;15(6):449-458. doi:10.1080/ 17425255.2019.1623878

8. Eriksson N, Wallentin L, Berglund L, et al. Genetic determinants of warfarin maintenance dose and time in therapeutic treatment range: a RE-LY genomics substudy. Pharmacogenomics. 2016;17 (13):1425-1439. doi:10.2217/pgs-2016-0061

9. Fawzy AM, Lip GY. Pharmacokinetics and pharmacodynamics of oral anticoagulants used in atrial fibrillation. Expert Opin Drug Metab Toxicol. 2019;15(5):381-398. doi:10.1080/ 17425255.2019 .1604686

10. Gage BF. Interview about the GIFT Trial, pharmacogenetics, and warfarin. Pharmacogenomics. 2017;18(15):1379-1380. doi:10.2217/ pgs-2017-0148

11. Gulseth MP, Grice GR, Dager WE. Pharmacogenomics of warfarin: uncovering a piece of the warfarin mystery. Am J Health Syst Pharm. 2009;66(2):123-133. doi:10.2146/ajhp080127

12. Johnson J, Caudle K, Gong L, et al. Clinical Pharmacogenetics Implementation Consortium (CPIC) guideline for pharmacogenetics-guided warfarin dosing: 2017 update. Clin Pharmacol Ther. 2017;102(3):397-404. doi:10.1002/cpt.668

13. Millican EA, Lenzini PA, Milligan PE, et al. Genetic-based dosing in orthopedic patients beginning warfarin therapy. Blood. 2007;110 (5):1511-1515. doi:10.1182/blood-2007-01-069609

14. Johnson JA, Cavallari LH. Warfarin pharmacogenetics. Trends Cardiovasc. 2015;25(1):33-41. doi:10.1016/j.tcm.2014.09.001

15. Mak M, Lam C, Pineda SJ, et al. Pharmacogenetics of warfarin in a diverse patient population. J Cardiovasc Pharmacol Ther. 2019;24 (6):521-533. doi:10.1177/1074248419843530

16. Emery JD. Pharmacogenomic testing and warfarin: what evidence has the GIFT trial provided? JAMA. 2017;318(12):1110-1112. doi:10.1001/jama.2017.11465

17. Al-Eitan L, Almasri A, Al-Habahbeh S. Impact of a variable number tandem repeat in the CYP2C9 promoter on warfarin sensitivity and responsiveness in Jordanians with cardiovascular disease. Pharmacogenomics Person Med. 2019;12:15-22. doi:10.2147/pgpm. s189838

18. Roden DM, Johnson JA, Kimmel SE, et al. Cardiovascular pharmacogenomics. Circ Res. 2011;109(7):807-820. doi:10.1161/ circresaha.110.230995

19. Cha P, Mushiroda T, Takahashi A, et al. Genome-wide association study identifies genetic determinants of warfarin responsiveness for Japanese. Hum Mol Genet. 2010;19(23):4735-4744. doi:10.1093/ $\mathrm{hmg} / \mathrm{ddq} 389$

20. Al-Eitan L, Almasri A, Khasawneh R. Impact of CYP2C9 and VKORC1 polymorphisms on warfarin sensitivity and responsiveness in Jordanian cardiovascular patients during the initiation therapy. Genes. 2018;9(12):578. doi:10.3390/genes9120578

21. Laxton R, Pearce E, Kyriakou T, Ye S. Association of the lymphotoxin- $\alpha$ gene Thr26Asn polymorphism with severity of coronary atherosclerosis. Genes Immun. 2005;6(6):539-541. doi:10.1038/sj. gene. 6364236

22. Wang X, Cheng S, Brophy VH, et al. A meta-analysis of candidate gene polymorphisms and ischemic stroke in 6 study populations. Stroke. 2009;40(3):683-695. doi:10.1161/ strokeaha.108.524587 
23. Liu Y, Sheng H, Lu L, et al. Haplotype-based association of four lymphotoxin-alpha gene polymorphisms with the risk of coronary artery disease in Han Chinese. Tohoku J Exp Med. 2011;224 (2):119-125. doi:10.1620/tjem.224.119

24. Pouladi N, Bime C, Garcia JG, Lussier YA. Complex genetics of pulmonary diseases: lessons from genome-wide association studies and next-generation sequencing. Transl Res. 2016;168:22-39. doi:10.1016/j.trsl.2015.04.016

25. Beitelshees AL, Navare H, Wang D, et al. CACNA1C gene polymorphisms, cardiovascular disease outcomes, and treatment response. Circ Cardiovasc Genet. 2009;2(4):362-370. doi:10.1161/ circgenetics.109.857839

26. Cooper GM, Johnson JA, Langaee TY, et al. A genome-wide scan for common genetic variants with a large influence on warfarin maintenance dose. Blood. 2008;112(4):1022-1027. doi:10.1182/blood2008-01-134247

27. Nolan D, Kraus WE, Hauser E, et al. Genome-wide linkage analysis of cardiovascular disease biomarkers in a large, multigenerational family. PLoS One. 2013;8(8):e71779. doi:10.1371/journal. pone. 0071779

28. Standaard Af handling cumarine interacties; 2003. Available from: www.fnt.nl. Accessed December 23, 2005.

29. Al-Eitan LN, Elsaqa BZ, Almasri AY, et al. Influence of PSRC1, CELSR2, and SORT1 gene polymorphisms on the variability of warfarin dosage and susceptibility to cardiovascular disease. Pharmacogenomics Person Med. 2020;13:619. doi:10.2147/PGPM. S274246

30. International Warfarin Pharmacogenetics Consortium. Estimation of the warfarin dose with clinical and pharmacogenetic data. $N$ Engl J Med. 2009;360(8):753-764. doi:10.1056/NEJMoa0809329

31. Higashi MK, Veenstra DL, Kondo LM, et al. Association between CYP2C9 genetic variants and anticoagulation-related outcomes during warfarin therapy. JAMA. 2002;287(13):1690-1698. doi:10.1001/ jama.287.13.1690
32. Panoulas VF, Nikas SN, Smith JP, et al. Lymphotoxin 252AG polymorphism is common and associates with myocardial infarction in patients with rheumatoid arthritis. Ann Rheum Dis. 2008;67 (11):1550-1556. doi:10.1136/ard.2007.082594

33. Clarke R, Xu P, Bennett D, et al. Lymphotoxin- $\alpha$ gene and risk of myocardial infarction in 6928 cases and 2712 controls in the ISIS Case-Control Study. PLoS Genet. 2006;2(7):e107. doi:10.1371/journal.pgen.0020107

34. Liu R, Cao J, Zhang Q, et al. Clinical and genetic factors associated with warfarin maintenance dose in northern Chinese patients with mechanical heart valve replacement. Medicine. 2017;96. doi:10.1097/ md.0000000000005658

35. Al-Eitan LN, Almasri AY, Khasawneh RH. Effects of CYP2C9 and VKORC1 polymorphisms on warfarin sensitivity and responsiveness during the stabilization phase of therapy. Saudi Pharm J. 2019;27 (4):484-490. doi:10.1016/j.jsps.2019.01.011

36. Piatkov I, Jones T, Mcle M. Drug interactions, pharmacogenomics and cardiovascular complication. Drug Discov. 2013;75. doi:10.5772/ 48423

37. Gamazon ER, Konkashbaev A, Derks EM, et al. Evidence of selection on splicing-associated loci in human populations and relevance to disease loci mapping. Sci Rep. 2017;7(1):1-15. doi:10.1038/ s41598-017-05744-9

38. Cavallari LH. Time to revisit warfarin pharmacogenetics. Future Cardiol. 2017;13:511-513. doi:10.2217/fca-2017-0061

39. Tang Q, Zou H, Guo C, Liu Z. Outcomes of pharmacogenetics-guided dosing of warfarin: a systematic review and meta-analysis. Int $J$ Cardiol. 2014;175(3):587-591. doi:10.1016/j.ijcard.2014.06.031

40. Al-Eitan L, Haddad Y. Emergence of pharmacogenomics in academic medicine and public health in Jordan: history, present state and prospects. Curr Pharmacogenomics Person Med. 2014;12:167-175. doi:10.2174/1875692113666150115221210
International Journal of General Medicine

\section{Publish your work in this journal}

The International Journal of General Medicine is an international, peer-reviewed open-access journal that focuses on general and internal medicine, pathogenesis, epidemiology, diagnosis, monitoring and treatment protocols. The journal is characterized by the rapid reporting of reviews, original research and clinical studies across all disease areas. The manuscript management system is completely online and includes a very quick and fair peer-review system, which is all easy to use. Visit http://www.dovepress.com/ testimonials.php to read real quotes from published authors. 